\title{
Associação entre o óleo de soja e o óleo de peixe na dieta de cabras em lactação como estratégia para melhorar o perfil de ácidos graxos do leite
}

\author{
[Association between soybean oil and fish oil in the diet of lactating goats as a strategy \\ to improve milk fatty acids profile] \\ A.L.M. Selegato ${ }^{1}$, R.S. Gentil ${ }^{1}$, C.P. Nolli ${ }^{1}$, E.M. Ferreira ${ }^{2}$, A.V. Pires ${ }^{1}$, O.C. Almeida ${ }^{3}$, \\ M.O.M. Parente ${ }^{4}$, D.M. Polizel ${ }^{1}$, I. Susin ${ }^{1 *}$ \\ ${ }^{1}$ Universidade de São Paulo - Escola Superior de Agricultura "Luiz de Queiroz" - Piracicaba, SP \\ ${ }^{2}$ Universidade Estadual de Ponta Grossa - Ponta Grossa, PR \\ ${ }^{3}$ Universidade Federal Rural de Pernambuco - Unidade Acadêmica de Garanhuns - Garanhuns, PE \\ ${ }^{4}$ Universidade Federal do Maranhão - Centro de Ciências Agrárias e Ambientais - Chapadinha, MA
}

\begin{abstract}
RESUMO
Os objetivos neste experimento foram avaliar os efeitos da associação entre o óleo de soja e o óleo de peixe na dieta de cabras em lactação sobre o consumo de matéria seca e de nutrientes, a variação do peso corporal, a produção e composição do leite, assim como o perfil de ácidos graxos. As cabras foram alocadas em baias individuais, onde receberam dieta composta por $50 \%$ de feno de "coastcross" e $50 \%$ de concentrado. Foram utilizadas nove cabras mestiças Boer x Saanen multíparas, distribuídas em três quadrados latinos 3 X 3 . O experimento teve duração de 51 dias, divididos em três períodos de 17 dias, sendo os 13 primeiros dias para adaptação dos animais às dietas e os 4 dias subsequentes para colheita de amostras e de dados. Os tratamentos experimentais foram: a) dieta controle (CT), sem adição de óleo; b) dieta contendo $3 \%$ de óleo de soja (OS); e c) dieta contendo $2,5 \%$ de óleo de soja $+0,5 \%$ de óleo de peixe $(\mathrm{OS}+\mathrm{P})$. A inclusão dos óleos reduziu $(\mathrm{P}<0,05)$ o consumo de matéria seca, no entanto aumentou $(\mathrm{P}<0,05)$ a eficiência alimentar dos animais, sem afetar $(\mathrm{P}>0,05)$ a produção de leite. Houve efeito $(\mathrm{P}<0,05)$ da dieta no perfil de ácidos graxos do leite, sendo que ambos os tratamentos com adição de óleo elevaram as concentrações de ácidos graxos de cadeia média e longa, reduzindo os de cadeia curta. $\mathrm{O}$ tratamento com a combinação do óleo de soja com o óleo de peixe foi o que promoveu os maiores aumentos na concentração de ácido vacênico (398\%), rumênico (352\%) e de CLA total (341\%) no leite. Os resultados permitem concluir que a suplementação lipídica elevou a eficiência alimentar dos animais e que o fornecimento de óleo de soja em combinação ao óleo de peixe aumentou a concentração no leite dos ácidos graxos benéficos à saúde humana.
\end{abstract}

Palavras-chave: CLA, composição do leite, desempenho

\begin{abstract}
The aims in this experiment were to determine the effects of the association between soybean and fish oils on dry matter intake (DMI) and nutrient intake, body weight change, milk production and composition and milk fatty acid profile of dairy goats. The animals were housed in tie stalls and fed a 50\% of coastcross hay and 50\% concentrate diet. Nine multiparous crossbred Boer $x$ Saanen goats were assigned in tree $3 X 3$ Latin Squares. The experimental period lasted 51 days; divided into three periods of 17 days, being the first nine days used to adapt goats to diets and the 4 other days for data collection. Experimental diets were: a) control diet (CT) without oil; b) control diet supplemented with $3 \%$ of soybean oil (SO); and c) control diet supplemented with $2.5 \%$ of soybean oil plus $0.5 \%$ of fish oil $(\mathrm{SO}+\mathrm{F})$. DMI was negatively influenced by oil addition. However, feed efficiency was higher in diets with oils, maintaining similar milk production ( $P>0.05$ for all comparisons). The supply of oils changed milk fatty acids profile $(P<0.05)$, increasing the concentrations of medium and long-chain fatty acids and
\end{abstract}

Recebido em 6 de outubro de 2014

Aceito em 18 de junho de 2015

* Autor para correspondência (corresponding author)

E-mail: ivasusin@usp.br 
reducing short-chain. Milk from goats fed the $\mathrm{SO}+\mathrm{F}$ diet had higher concentration of vaccenic (398\%), rumenic acid (352\%) and total CLA (341\%). The results indicate that the oil supply increased the feed efficiency of goats, and that the combination of soybean and fish oils caused a higher elevation of fatty acids considered to have health benefits.

Keywords: CLA, milk composition, performance

\section{INTRODUÇÃO}

O consumo de carne e produtos lácteos provenientes de ruminantes está frequentemente associado à incidência de doenças cardiovasculares por apresentar elevada concentração de ácidos graxos saturados (Jenkins et al., 2008). Porém, como os efeitos maléficos estão diretamente ligados à fração lipídica, sendo esta o componente do leite mais susceptível à manipulação via dieta (Lucas et al., 2008), pesquisadores têm concentrado esforços no sentido de promover alterações benéficas no perfil lipídico do leite de ruminantes.

Os ácidos linoleicos conjugados (CLA) têm despertado a atenção por desempenhar diversas atividades benéficas à saúde humana, como: ação anticarcinogênica (Bhattacharya et al., 2006), redução na deposição de gordura corpórea (Jiang et al., 2010), alterações na partição de nutrientes (Park et al., 1997), redução no risco de desenvolvimento de doenças cardiovasculares (Pfeuffer e Scherenmeir, 2000) e modulação do sistema imune (Hu et al., 2007).

Levando em consideração que a principal fonte natural de CLA na alimentação humana é o leite de ruminantes e derivados (Bauman et al., 2006), vários estudos visando manipular o metabolismo ruminal para elevar o conteúdo de ácidos graxos benéficos vêm sendo realizados $\mathrm{e}$, até $\mathrm{o}$ momento, a introdução de fontes de ácidos graxos insaturados às dietas dos animais tem apresentado os resultados mais promissores (Eifert et al., 2006; Matsushita et al., 2007).

A elevação da concentração de CLA no leite de ruminantes suplementados com fontes lipídicas é decorrente do maior aporte de precursores (ácido linoleico e ácido linolênico) para síntese ruminal do CLA e do ácido vacênico (C18:1 trans-11) (Harfoot e Hazlewood, 1997).

Apesar de o óleo de peixe não apresentar elevada concentração de ácido linoleico e linolênico, a elevação de CLA no leite de animais que o consome é decorrente da inibição do grupo de bactérias, genericamente denominadas Grupo B, responsáveis pelo último passo da biohidrogenação do ácido vacênico a ácido esteárico; com isso, maior quantidade de ácido vacênico chega ao lúmen intestinal passível de ser absorvido e posteriormente convertido em CLA pela $\Delta^{9}$ - desaturase entérica e mamária (Chilliard et al., 2003).

Portanto, o presente experimento teve como objetivo avaliar os efeitos da complementaridade entre uma fonte rica em ácido linoleico (óleo de soja) e outra rica no ácido graxo docosahexaenoico (DHA) que é capaz de inibir o último passo da biohidrogenação ruminal sobre o desempenho e o perfil de ácidos graxos do leite de cabras.

\section{MATERIAL E MÉTODOS}

O estudo foi conduzido nas instalações do Sistema Intensivo de Produção de Ovinos e Caprinos (SIPOC) do Departamento de Zootecnia da Escola Superior de Agricultura Luiz de Queiroz, localizada em Piracicaba - SP, Brasil.

O protocolo de pesquisa e os procedimentos com os animais usados neste experimento foram aprovados pela Comissão de Ética no Uso de Animais em Pesquisa (CEUAP) da Escola Superior de Agricultura Luiz de Queiroz (protocolo 2011/15).

A partir de um grupo de 35 cabras em lactação, foram selecionadas nove cabras mestiças Boer $\mathrm{x}$ Saanen multíparas, com peso corporal médio de $58 \pm 14 \mathrm{~kg}$ e produção média no início do experimento de $1,7 \pm 0,6 \mathrm{~kg}$ de leite, com $64 \pm 3$ dias de lactação. As cabras foram alocadas em galpão coberto, em baias individuais do tipo "tiestall”, medindo $0,50 \times 1,2 \mathrm{~m}$, com piso ripado, providas de comedouro individual e bebedouro.

O delineamento experimental foi o quadrado latino triplo $(3 \times 3)$, sendo que o experimento 
teve duração de 51 dias, os quais foram divididos em três períodos de 17 dias, sendo os 13 primeiros dias para adaptação às dietas experimentais e os 4 dias subsequentes para a colheita de dados e de amostras. Os tratamentos experimentais consistiram em uma dieta controle (CT), sem adição de óleo; uma dieta contendo $3 \%$ de óleo de soja (OS); e outra dieta contendo $2,5 \%$ de óleo de soja $+0,5 \%$ de óleo de peixe $(\mathrm{OS}+\mathrm{P})$ (Tab. 1). Os teores de inclusão dos óleos nas dietas foram definidos de acordo com experimento prévio realizado com ovelhas lactantes (Ferreira et al., 2014). As rações experimentais foram isonitrogenadas, contendo $50 \%$ de volumoso e $50 \%$ de concentrado, formuladas conforme as recomendações do NRC (2007) para atender às exigências nutricionais de cabras em lactação. A proporção dos ingredientes e composição química das rações experimentais encontram-se na Tabela 1. O perfil de ácidos graxos dos óleos utilizados encontra-se na Tabela 2.

Tabela 1. Proporção dos ingredientes e composição química das dietas experimentais (\% da MS)

\begin{tabular}{lccc}
\hline \multirow{2}{*}{ Item } & \multicolumn{3}{c}{ Dietas $^{1}$} \\
\cline { 2 - 3 } & $\mathrm{CT}$ & $\mathrm{OS}$ & $\mathrm{OS}+\mathrm{P}$ \\
\hline Ingredientes & & & 50,0 \\
Feno de coastcross & 50,0 & 50,0 & 33,8 \\
Milho moído & 37,6 & 33,8 & 10,2 \\
Farelo de Soja & 9,4 & 10,2 & 0,5 \\
Ureia & 0,5 & 0,5 & 2,5 \\
Mistura mineral & 2,5 & 2,5 & 0,5 \\
Óleo de peixe & - & - & 2,5 \\
Óleo de soja & - & 2,5 & \\
Composição química & & & 89,17 \\
Matéria seca (\% da MO) & 89,3 & 13,2 \\
Proteína bruta & 13,0 & 13,2 & 5,2 \\
Extrato etéreo $_{\text {Fibra em detergente neutro }}$ & 2,5 & 5,3 & 49,4 \\
Matéria mineral & 48,1 & 50,6 & 2,1 \\
Energia líquida $^{3}$ & 2,1 & 2,1 & 1,6 \\
\hline
\end{tabular}

${ }^{\mathrm{I}}$ CT: sem inclusão de óleo; OS: $3 \%$ óleo de soja; OS+P: $2,5 \%$ óleo de soja $+0,5 \%$ óleo de peixe. ${ }^{2}$ Composição: $7,5 \%$ P; 13,4\% Ca; $1 \% \mathrm{Mg} ; 7 \% \mathrm{~S} ; 14,5 \% \mathrm{Na} ; 21,8 \% \mathrm{Cl} ; 500 \mathrm{ppm}$ Fe; 300ppm Cu; 4.600 ppm Zn; 1.100 ppm Mn; 55 ppm I; 40 ppm Co; 30 ppm Se. ${ }^{3}$ Energia líquida de lactação - estimado utilizando o modelo SRNS, v. 1.8.7 (Tedeschi et al., 2008).

Tabela 2. Perfil de ácidos graxos do óleo de soja e do óleo de peixe

\begin{tabular}{lcc}
\hline Ácidos graxos, g/100g & Óleo de soja & Óleo de peixe \\
\hline C12:0 (láurico) & n.d. & n.d. \\
C14:0 (mirístico) & 0,08 & 1,31 \\
C16:0 (palmítico) & 11,32 & 12,07 \\
C16:1 (palmitoleico) & n.d. & 1,29 \\
C18:0 (esteárico) & 4,05 & 3,46 \\
C18:1 $\omega-9$ (oleico) & 23,38 & 21,96 \\
C18:2 $\omega-6$ (linoleico) & 54,79 & 47,55 \\
C18:3 $\omega-3$ (linolênico) & 4,9 & 5,19 \\
C20:5 $\omega-3$ (EPA - eicosapentaenoico) & n.d. & 2,86 \\
C22:6 $\omega-3$ (DHA - docosahexaenoico) & n.d. & 3,11 \\
Saturados & 15,64 & 17,55 \\
PUFA ${ }^{1}$ & 60,98 & 59,06 \\
MUFA & 23,38 & 23,39 \\
PUFA $\omega-6$ & 23,38 & 47,55 \\
PUFA $\omega-3$ & 56,08 & 11,51 \\
\hline
\end{tabular}

${ }^{\mathrm{T}}$ PUFA: ácidos graxos poli-insaturados. ${ }^{2}$ MUFA: ácidos graxos monoinsaturados. ${ }^{3}$ n.d.: não detectado. 
Uma vez por dia as rações foram pesadas em balança de precisão de $10 \mathrm{~g}$ e ofertadas ad libitum. No momento anterior à oferta, os óleos foram misturados aos ingredientes concentrados das rações e posteriormente ao feno de "coastcross". Diariamente, as sobras de ração foram pesadas, amostradas $(10 \%)$ e conservadas a $-20^{\circ} \mathrm{C}$ para posterior análise. A quantidade de ração ofertada foi definida com base no consumo do dia anterior, de modo que as sobras não fossem superiores a $10 \%$ da quantidade ofertada.

Para avaliação da variação no peso corporal, as cabras foram pesadas em três dias consecutivos sem jejum alimentar, sendo as pesagens realizadas no início do experimento e no final de cada período.

No decorrer do experimento, as cabras foram ordenhadas duas vezes ao dia (7h30 e 15h30). Entre o $14^{\circ}$ e $17^{\circ}$ dia de cada período experimental, a produção de leite foi mensurada através de pesagem em balança de precisão. A produção de leite corrigida para $3,5 \%$ de gordura (LCG) foi determinada utilizando-se a fórmula: $\mathrm{LCG}=(0,432+0,1625 \times \%$ de gordura do leite $)$ $\mathrm{x} \mathrm{kg}$ de leite, conforme proposto por Sklan et al. (1992). Entre o $14^{\circ}$ e o $17^{\circ}$ dia de cada período, logo após a pesagem, amostras compostas do leite de cada cabra (ordenha da manhã e ordenha da tarde) foram colhidas e conservadas em frascos de $40 \mathrm{~mL}$, contendo 2-bromo-2nitropropano-1-3-diol para posterior determinação dos teores de proteína, gordura, lactose e sólidos totais. Para a determinação do perfil de ácidos graxos, foram colhidas amostras de leite $(60 \mathrm{~mL})$, compostas por animal e por período experimental. Essas amostras foram acondicionadas em garrafas plásticas previamente identificadas e armazenadas a $20^{\circ} \mathrm{C}$.

No terceiro dia de cada período, antes da oferta do alimento, foram colhidas amostras de sangue via punção da veia jugular, em tubos a vácuo (BD VacutainerTM) com gel separador inerte para soro e ativador de coágulo. Imediatamente após a colheita, as amostras foram centrifugadas para obtenção do soro, o qual foi armazenado em tubetes plásticos (tipo eppendorf) e congelados ($20^{\circ} \mathrm{C}$ ) para posterior determinação laboratorial dos ácidos graxos não esterificados (AGNE).
Após o término do experimento, as amostras de sobra das rações foram descongeladas e compostas por animal e por período experimental. Em seguida, juntamente com as amostras da ração ofertada, foram moídas em moinho provido de peneira com crivos de $1 \mathrm{~mm}$. As determinações da matéria seca (MS), matéria mineral (MM) e proteína bruta $(\mathrm{PB})$ foram realizadas segundo a AOAC (1990). A fibra insolúvel em detergente neutro (FDN) foi determinada conforme Van Soest et al. (1991), utilizando-se sulfito de sódio e $\alpha$-amilase termoestável.

As determinações dos teores de proteína, gordura, lactose e sólidos totais do leite foram realizadas por meio de leitura de absorção de infravermelho próximo, utilizando-se o equipamento Bentley 2000 (Bentley Instruments Inc., Minessota, EUA), pertencente ao Laboratório de Análise de Leite, da Clínica do Leite, da Escola Superior de Agricultura Luiz de Queiroz, Universidade de São Paulo ESALQ/USP.

Para determinação do perfil de ácidos graxos do leite, as amostras foram descongeladas em banho-maria a uma temperatura de $40^{\circ} \mathrm{C}$ e centrifugadas. Os lipídeos totais do leite foram extraídos segundo a metodologia descrita por Feng et al. (2004). Uma alíquota de aproximadamente $65 \mathrm{mg}$ da gordura foi metilada em duas etapas com $2 \mathrm{~mL}$ de $0,5 \mathrm{M}$ de metóxido de sódio $\left(10\right.$ minutos a $\left.50^{\circ} \mathrm{C}\right)$, com posterior adição de HCL metanoico e incubação em banho-maria a $80^{\circ} \mathrm{C}$ por 10 minutos, de acordo com metodologia descrita por Kramer et al. (1997). Após a metilação, as amostras foram armazenadas a $-20^{\circ} \mathrm{C}$, em frascos âmbar de $1,5 \mathrm{~mL}$, contendo nitrogênio para evitar possível oxidação lipídica.

Para a quantificação e determinação dos AGs, foi utilizado um cromatógrafo gasoso Agilent Technologies 7890A, com detector de ionização de chama (7683B), e coluna capilar de sílica fundida $(\mathrm{J} \& \mathrm{~W}$ 112-88A7, Agilent Technologies) de $100 \mathrm{~m}$ de comprimento e $25 \mu \mathrm{m}$ de diâmetro interno, revestida com $0,20 \mu \mathrm{m}$ de cianopropil policiloxano. A aquisição dos dados foi feita por meio do software ChemStation (Agilent Technologies, Palo Alto, CA, EUA). O tempo total da corrida cromatográfica foi de 87,5 minutos, os quais foram divididos em quatro 
rampas de aquecimento: primeira, com temperatura inicial de $70^{\circ} \mathrm{C}$ mantida durante 1 minuto, aumentando gradativamente $\left(5^{\circ} \mathrm{C} / \mathrm{min}\right)$ até atingir $100^{\circ} \mathrm{C}$, temperatura esta mantida durante 2 minutos; segunda, com aumento de $10^{\circ} \mathrm{C} /$ minuto, atingindo $175^{\circ} \mathrm{C}$ e mantida durante 40 minutos; terceira rampa de aquecimento, com aumento até $225^{\circ} \mathrm{C}$ a uma taxa de $5^{\circ} \mathrm{C} / \mathrm{min}$; e rampa final, com aumento até a temperatura final de $245^{\circ} \mathrm{C}$ a uma taxa de $20^{\circ} \mathrm{C} / \mathrm{min} ; 20 \mathrm{~min}$, mantida durante 1 minuto. $\mathrm{O} \mathrm{H}_{2}$ foi utilizado como gás de arraste em uma vazão de $1,0 \mathrm{~mL} / \mathrm{min}$; a temperatura do injetor e do detector foi de $260^{\circ} \mathrm{C}$. O $\mathrm{N}_{2}$ foi utilizado como Makeup, com vazão de $30 \mathrm{~mL} / \mathrm{min}$. Foi utilizada opção split em uma relação 50:1. A identificação dos ácidos graxos das amostras foi realizada com base no tempo de retenção dos ésteres metílicos dos ácidos graxos dos padrões. Utilizou-se um padrão de 37 compostos (Supelco mix C4 C24/n. 18919), e padrões individuais para a identificação dos ácidos graxos C18:0, C18:2 cis-9, trans-11 e C18:2 trans-10, cis-12 (NuChek Prep, Elysian, MN).

A concentração de ácidos graxos não esterificados foi determinada com a utilização do kit comercial (NEFA-C Wako Chemicals ${ }^{\circledR}$, Richmond, Virginia - USA) adaptado para leitura em placas de microtítulo, em aparelho tipo Elisa Reader (BIO RAD Laboratories, Hercules, CA, EUA) com comprimento de luz de 540 nanômetros.

Os dados foram analisados utilizando-se o PROC MIXED do SAS (2004), e as médias foram obtidas pelo comando LSMEANS e comparadas pelo teste Tukey, sendo consideradas significativas quando $\mathrm{P}<0,05$.

\section{RESULTADOS}

A introdução de óleo de soja ou da mistura óleo de soja e óleo de peixe ocasionou diferentes respostas nos parâmetros fisiológicos e produtivos dos animais (Tab. 3, 4 e 5).

Os tratamentos com óleo reduziram $(\mathrm{P}<0,01)$ o consumo de matéria seca (CMS) (Tab. 3). Como esperado, o consumo de extrato etéreo (CEE) aumentou em resposta à inclusão das fontes lipídicas nas dietas. Não houve efeito $(\mathrm{P}>0,05)$ da adição de óleo de soja ou da mistura óleo de soja e óleo de peixe sobre o consumo de fibra insolúvel em detergente neutro (CFDN). O consumo de proteína bruta $(\mathrm{CPB})$ reduziu com o fornecimento da mistura óleo de soja e óleo de peixe $(\mathrm{P}<0,01)$, no entanto não foi afetado pelo fornecimento de óleo de soja $(\mathrm{P}>0,05)$.

Tabela 3. Consumo de matéria seca e de nutrientes pelas cabras alimentadas com as rações experimentais

\begin{tabular}{lcccccc}
\hline \multirow{2}{*}{ Item } & \multicolumn{3}{c}{ Dietas $^{1}$} & \multirow{2}{*}{ EPM $^{6}$} & \multirow{2}{*}{ Efeito $(\mathrm{P}>\mathrm{F})^{7}$} \\
\cline { 2 - 4 } $\mathrm{CMS}^{2}, \mathrm{~kg} / \mathrm{d}$ & $\mathrm{CT}$ & OS & OS $+\mathrm{P}$ & & & $<0,01$ \\
$\mathrm{CFDN}^{3}, \mathrm{~kg} / \mathrm{d}$ & $1,72 \mathrm{a}$ & $1,59 \mathrm{~b}$ & $1,54 \mathrm{~b}$ & & 0,05 & 0,13 \\
$\mathrm{CPB}^{4}, \mathrm{~kg} / \mathrm{d}$ & 0,79 & 0,77 & 0,74 & & 0,02 & $<0,01$ \\
$\mathrm{CEE}^{5}, \mathrm{~kg} / \mathrm{d}$ & $0,23 \mathrm{a}$ & $0,21 \mathrm{ab}$ & $0,20 \mathrm{~b}$ & $<0,01$ & $<0,01$ \\
\hline
\end{tabular}

${ }^{\mathrm{T}} \mathrm{CT}=$ sem inclusão de óleos; OS $=3 \%$ óleo de soja; OS+P $=2,5 \%$ óleo de soja $+0,5 \%$ óleo de peixe. ${ }^{2}$ Consumo de matéria seca. ${ }^{3}$ Consumo de fibra em detergente neutro. ${ }^{4}$ Consumo de proteína bruta. ${ }^{5}$ Consumo de extrato etéreo. ${ }^{6}$ EPM: Erro padrão da média. ${ }^{7}$ Probabilidade de haver diferença entre os tratamentos $(\mathrm{P}<0,05)$. Valores seguidos por letras distintas na mesma linha diferem estatisticamente $(\mathrm{P}<0,05)$.

A produção diária de leite e de leite corrigido para 3,5\% de gordura (LCG) não foi influenciada $(\mathrm{P}>0,05)$ pelos tratamentos (Tab. 4). No entanto, o fornecimento de óleo de soja e a mistura óleo de soja e óleo de peixe melhorou a eficiência alimentar (EA) dos animais $(\mathrm{P}<0,01)$ (Tab. 4).

As concentrações e as produções de gordura, lactose e proteína, e a concentração dos ácidos graxos não esterificados (AGNE) não foram influenciadas pelos tratamentos $(\mathrm{P}>0,05)$. Da mesma forma, não houve efeito das dietas
$(\mathrm{P}>0,05)$ sobre a produção de sólidos totais. No entanto, o teor de sólidos totais foi superior $(\mathrm{P}=0,02)$ no leite das cabras que receberam o óleo de soja ou a mistura óleo de soja e óleo de peixe (Tab. 4).

O fornecimento de óleo de soja ou da mistura óleo de soja e óleo de peixe aumentou $(\mathrm{P}<0,01)$ a concentração de ácido esteárico (C18:0), ácido vacênico (C18:1 t11) e ácido linoleico (C18:2) no leite (Tab. 5). 
Tabela 4. Produção de leite, eficiência alimentar, composição do leite, variação do peso corporal e concentração de ácidos graxos não esterificados no sangue das cabras alimentadas com as rações experimentais

\begin{tabular}{|c|c|c|c|c|c|}
\hline \multirow{2}{*}{ Item } & \multicolumn{3}{|c|}{ Dietas $^{1}$} & \multirow{2}{*}{$\mathrm{EPM}^{2}$} & \multirow{2}{*}{ Efeito $(\mathrm{P}>\mathrm{F})^{3}$} \\
\hline & $\mathrm{CT}$ & $\mathrm{OS}$ & $\mathrm{OS}+\mathrm{P}$ & & \\
\hline Produção de leite, $\mathrm{kg} / \mathrm{d}$ & 1,49 & 1,45 & 1,39 & 0,07 & 0,49 \\
\hline $\mathrm{LCG}^{4}, \mathrm{~kg} / \mathrm{d}$ & 1,65 & 1,7 & 1,65 & 0,09 & 0,75 \\
\hline Eficiência Alimentar ${ }^{4}$ & $0,95 \mathrm{~b}$ & $1,06 \mathrm{a}$ & $1,05 \mathrm{a}$ & 0,04 & $<0,01$ \\
\hline Gordura, $\%$ & 4,17 & 4,57 & 4,69 & 0,23 & 0,06 \\
\hline Gordura, g/d & 62,3 & 65,9 & 64,7 & 4,19 & 0,37 \\
\hline Lactose, $\%$ & 4,51 & 4,56 & 4,51 & 0,04 & 0,70 \\
\hline Lactose, $\mathrm{g} / \mathrm{d}$ & 67,2 & 66,2 & 63,3 & 3,29 & 0,61 \\
\hline Proteína, $\%$ & 3,65 & 3,74 & 3,79 & 0,09 & 0,33 \\
\hline Proteína, g/d & 53,6 & 54,4 & 52,6 & 2,55 & 0,77 \\
\hline Sólidos totais, $\%$ & $13,1 \mathrm{~b}$ & $13,7 \mathrm{a}$ & $13,8 \mathrm{a}$ & 0,32 & 0,02 \\
\hline Sólidos totais, $\mathrm{g} / \mathrm{d}$ & 195 & 199 & 192 & 9,86 & 0,76 \\
\hline $\mathrm{VPC}^{4}, \mathrm{~kg}$ & $1,7 \mathrm{a}$ & $0,65 \mathrm{ab}$ & $0,03 \mathrm{~b}$ & 0,28 & 0,04 \\
\hline $\mathrm{AGNE}^{4}, \mathrm{mmol} / \mathrm{L}$ & 0,28 & 0,45 & 0,38 & 0,03 & 0,12 \\
\hline
\end{tabular}

${ }^{\mathrm{T}} \mathrm{CT}=$ sem inclusão de óleos; $\mathrm{OS}=3 \%$ óleo de soja. OS $+\mathrm{P}=2,5 \%$ óleo de soja $+0,5 \%$ óleo de peixe. ${ }^{2}$ EPM: Erro padrão da média. ${ }^{3}$ Probabilidade de haver diferença entre as dietas $(\mathrm{P}<0,05)$. ${ }^{4} \mathrm{LCG}$ : leite corrigido para $3,5 \%$ de gordura; eficiência alimentar = LCG/consumo matéria seca; VPC: variação de peso corporal; AGNE: ácidos graxos não esterificados. Valores seguidos por letras distintas na mesma linha diferem estatisticamente $(\mathrm{P}<0,05)$.

Em comparação à dieta controle, o fornecimento de óleo de peixe misturado ao óleo de soja aumentou $(\mathrm{P}<0,01)$ a concentração dos isômeros de CLA C18:2 c9, t11 (ácido rumênico) e C18:2 t10, c12 no leite. No entanto, a concentração desses isômeros não diferiu entre as dietas contendo óleo de soja ou a mistura óleo de soja e óleo de peixe (Tab. 5).

A concentração dos ácidos graxos de cadeia média (C14 a C16:0), longa (C17:0 a C22:6), insaturados totais, monoinsaturados (MUFA) e poli-insaturados (PUFA) e a relação insaturados:saturados foi superior $(\mathrm{P}<0,01)$ no leite das cabras alimentadas com as dietas contendo óleo de soja ou a mistura óleo de soja e óleo de peixe em comparação à dieta controle. Para esses compostos, não houve diferença $(\mathrm{P}>0,05)$ entre as dietas com óleo (Tab. 5). Em comparação à dieta controle, o fornecimento de óleo de peixe misturado ao óleo de soja reduziu $(\mathrm{P}<0,01)$ a concentração dos ácidos graxos de cadeia curta no leite, não havendo diferença $(\mathrm{P}>0,05)$ entre as fontes de óleo. Como esperado, o óleo de peixe foi eficiente em reduzir $(\mathrm{P}<0,05)$ a concentração dos ácidos graxos saturados no leite, quando comparado à dieta controle (Tab. 5).

\section{DISCUSSÃO}

Apesar de a inclusão do óleo de soja ou da mistura óleo de soja e óleo de peixe ter sido relativamente pequena, em média $3,0 \%$ da $\mathrm{MS}$, o menor CMS pelos animais alimentados com as dietas contendo óleo pode ser atribuído à maior densidade energética dessas dietas em comparação à dieta controle (Tab. 1). Esse resultado é condizente com a melhora na eficiência alimentar das cabras que receberam as dietas contendo as fontes de óleo (Tab.4).

A ausência de alterações significativas na concentração de gordura no leite $(\%)$ e na quantidade de gordura produzida por dia $(\mathrm{g} / \mathrm{d})$ é condizente com outros experimentos em que ruminantes receberam dietas contendo fontes de óleo (Loor et al., 2005). Com relação ao teor de sólidos totais, o menor valor no leite dos animais alimentados com a dieta controle $(\mathrm{P}<0,05)$ pode ter ocorrido devido ao fato de os tratamentos com óleo de soja e óleo de peixe misturado ao óleo de soja, apesar de não terem tido diferença estatística $(\mathrm{P}=0,06)$, apresentarem valores de teor de gordura 11 e $12 \%$, respectivamente, superiores à dieta controle. 
Associação entre o óleo...

Tabela 5. Perfil de ácidos graxos (g/100g de ácido graxo) da gordura do leite de cabras alimentadas com as rações experimentais $(\%)$

\begin{tabular}{lccccc}
\hline \multirow{2}{*}{ Item $^{1}$} & \multicolumn{3}{c}{ Dietas $^{2}$} & \multirow{2}{*}{ EPM $^{3}$} & Efeito $^{(P>F)^{4}}$ \\
\cline { 2 - 4 } C18:0 (esteárico) & $\mathrm{CT}$ & $\mathrm{OS}$ & $\mathrm{OS}+\mathrm{P}$ & & \\
C18:1 (oleico) & $9,08 \mathrm{~b}$ & $14,76 \mathrm{a}$ & $13,09 \mathrm{a}$ & 0,68 & $<0,01$ \\
C18:1 t11 (vacênico) & 21,12 & 24,03 & 23,85 & 0,55 & 0,09 \\
C18:2 c9, t11 (rumênico) & $0,86 \mathrm{~b}$ & $3,16 \mathrm{a}$ & $4,28 \mathrm{a}$ & 0,41 & $<0,01$ \\
C18:2 (t10, c12) & $0,27 \mathrm{~b}$ & $0,83 \mathrm{ab}$ & $1,22 \mathrm{a}$ & 0,12 & $<0,01$ \\
C18:2 (linoleico) & $0,02 \mathrm{~b}$ & $0,03 \mathrm{ab}$ & $0,06 \mathrm{a}$ & $<0,01$ & 0,03 \\
Cadeia curta (C4:0-C12:0) & $43,6 \mathrm{~b}$ & $53,9 \mathrm{a}$ & $55,5 \mathrm{a}$ & 1,26 & $<0,01$ \\
Cadeia média (C14:0-C16:0) & $17,49 \mathrm{a}$ & $15,15 \mathrm{ab}$ & $13,05 \mathrm{~b}$ & 0,55 & $<0,01$ \\
Cadeia longa (C17:0-C22:0) & $38,95 \mathrm{a}$ & $31,03 \mathrm{~b}$ & $29,82 \mathrm{~b}$ & 0,91 & $<0,01$ \\
Saturados totais & $43,6 \mathrm{~b}$ & $53,92 \mathrm{a}$ & $55,5 \mathrm{a}$ & 1,26 & $<0,01$ \\
Insaturados totais & $74,35 \mathrm{a}$ & $67,7 \mathrm{ab}$ & $65,32 \mathrm{~b}$ & 1,28 & 0,01 \\
Insaturados:saturados & $25,69 \mathrm{~b}$ & $32,4 \mathrm{a}$ & $33,05 \mathrm{a}$ & 0,95 & $<0,01$ \\
MUFA & $0,34 \mathrm{~b}$ & $0,48 \mathrm{a}$ & $0,52 \mathrm{a}$ & 0,02 & 0,01 \\
PUFA & $22,72 \mathrm{~b}$ & $28,55 \mathrm{a}$ & $28,63 \mathrm{a}$ & 0,81 & $<0,01$ \\
CLA total & $2,97 \mathrm{~b}$ & $3,85 \mathrm{a}$ & $4,43 \mathrm{a}$ & 0,18 & $<0,01$ \\
M & $0,29 \mathrm{~b}$ & $0,87 \mathrm{ab}$ & $1,28 \mathrm{a}$ & 0,12 & $<0,01$ \\
\hline
\end{tabular}

${ }^{1}$ MUFA: ácidos graxos monoinsaturados; PUFA: ácidos graxos poli-insaturados. ${ }^{2} \mathrm{CT}=$ sem inclusão de óleos; OS = $3 \%$ óleo de soja; $\mathrm{OS}+\mathrm{P}=2,5 \%$ óleo de soja $+0,5 \%$ óleo de peixe. ${ }^{3} \mathrm{EPM}$ : Erro padrão da média. ${ }^{4}$ Probabilidade de haver diferença entre os tratamentos $(\mathrm{P}<0,05)$. Valores seguidos por letras distintas na mesma linha diferem estatisticamente $(\mathrm{P}<0,05)$.

Apesar de o fornecimento de óleo de peixe misturado ao óleo de soja ter elevado a concentração do CLA trans-10 cis-12 em 200\%, não foi observada diminuição na produção de gordura no leite das cabras. Esse ácido graxo está relacionado à diminuição na produção de gordura no leite, principalmente em vacas (Peterson et al., 2003; Loor et al., 2005). Porém, em pequenos ruminantes, esse efeito é observado apenas quando há adição de fontes sintéticas desse ácido graxo (Schmidely e Morand-Fehr, 2004; Lock et al., 2006; Sinclair et al., 2007).

Essas observações sugerem que a glândula mamária desses animais pode ser menos sensitiva ao efeito do CLA trans-10, cis-12 na síntese de gordura do leite, quando comparada à de vacas, concluindo, portanto, que a regulação da síntese de gordura do leite difere-se entre essas espécies (Reynolds et al., 2006).

O aumento na concentração de ácido esteárico no leite em resposta ao fornecimento das dietas contendo óleo de soja ou a mistura óleo de soja e óleo de peixe se justifica pelo maior aporte de precursores (ácidos graxos C18) para biohidrogenação ruminal. O presente resultado é coerente com os valores obtidos por $\mathrm{Li}$ et al. (2012), que constataram que a suplementação de cabras em lactação com óleo de soja ou de açafrão ocasionou elevação da concentração do C18:0 no leite dos animais.

Sugere-se que a elevação da concentração do ácido vacênico (C18:1 trans-11) foi proporcionada pelo maior aporte de precursores (ácidos graxos C18) para sua síntese ruminal e, no caso da dieta contendo óleo de peixe misturado ao óleo de soja, a maior elevação percentual foi decorrente da inibição do grupo de bactérias, genericamente denominadas Grupo B, responsável pelo passo final da biohidrogenação total dos ácidos graxos. Essa inibição é conferida pelos ácidos graxos eicosapentaenoico (EPA) e docosahexaenoico (DHA) presentes no óleo de peixe (Maia et al., 2006). Adicionalmente, observou-se que, no leite dos animais que receberam a mistura óleo de soja e óleo de peixe, quando comparado ao controle, houve acentuada elevação $(352 \%)$ na concentração do isômero C18:2 cis-9 trans-11 (rumênico) ocasionada pelo maior fornecimento de seu precursor, o ácido vacênico, para a glândula mamária, tecido responsável pela síntese de mais de $80 \%$ do ácido rumênico encontrado no leite (Mosley et al., 2006).

A concentração do ácido linoleico (C18:2 cis9, cis12) no leite foi elevada pela adição de óleos nas dietas e acompanhou o maior aporte desses 
ácidos graxos promovido pelo óleo de soja. Apesar da menor concentração do ácido linoleico presente no óleo de peixe em comparação ao óleo de soja (Tab. 2), não foi observada diferença entre os tratamentos, o que pode ser explicado pela atividade inibitória do EPA e DHA, presentes no óleo de peixe, sobre a biohidrogenação do ácido linoleico (Wasowska et al., 2006).

Acompanhando a elevação da concentração dos outros intermediários do ácido linoleico avaliados (ácido vacênico e rumênico), a adição do óleo de peixe elevou a concentração do isômero C18:2 t10, c12. A diferença numérica em favor do tratamento contendo óleo de peixe comprova o poder de inibição do EPA e DHA sobre o passo final da biohidrogenação desse ácido graxo.

Ratificando a atividade inibitória do EPA e DHA sobre o último passo da hidrogenação ruminal, a concentração total de ácidos graxos insaturados do leite das cabras foi elevada pelas dietas contendo óleo de soja e/ou a mistura óleo de soja e óleo de peixe em relação à dieta controle. As dietas com fontes de óleo promoveram elevação da concentração de MUFA e PUFA no leite, acompanhando a elevação da sua ingestão propiciada pela inclusão das fontes, além da elevação da concentração de intermediários da biohidrogenação do ácido linoleico.

\section{CONCLUSÕES}

A adição de óleo de soja e de peixe promoveu melhor perfil de ácidos graxos no leite de cabras, com maiores concentrações de ácidos graxos de cadeia longa e insaturados sem alterar a produção e composição química do leite. Adicionalmente, a associação do óleo de peixe ao óleo de soja elevou as concentrações dos isômeros do CLA e ácido vacênico, possibilitando assim produção de leite com gordura mais saudável à alimentação humana.

\section{REFERÊNCIAS}

BHATTACHARYA, A.; BANU, J; RAHMAN, M. et al. Biological effects of conjugated linoleic acids in health and disease. J. Nut. Biochem., v.17, p.789-810, 2006.
BAUMAN, D.E.; MATHER, I.H.; WALL, R.J.; LOCK, A.L. Major advances associated with the biosynthesis of milk. J. Dairy Sci., v.9, p.12351243. 2006.

CHILLIARD, Y.; FERLAY, A.; ROUEL, A.; LAMBERET, G. A review of nutritional and physiological factors affecting goat milk lipid synthesis and lipolysis. J. Dairy Sci., v.86, p.1751-1770, 2003.

EIFERT, E.C.; LANA, R.P.; LANNA, D.P.D. et al. Consumo, produção e composição do leite de vacas alimentadas com óleo de soja e diferentes fontes de carboidratos na dieta. Rev. Bras. Zootec., v.35, p.211-218, 2006.

FENG, S.; LOCK A.L.; GANSWORTHY, P.C. Technical note: a rapid lipid separation method for determining fatty acid composition of milk. $J$. Dairy Sci., v.85, p.3785-3788, 2004.

FERREIRA, E.M.; PIRES, A.V.; SUSIN, I et al. Lamb performance, milk production and composition from ewes supplemented with soybean oil partially replaced by fish oil blend. Livest. Sci., v.163, p.51-61, 2014.

HARFOOT, C.G.; HAZLEWOOD, G.P. Lipid metabolism in the rumen. In: HOBSON, P.N.; STEWART, C.S. (Eds.). The ruminal microbial ecosystem. London: Chapman \& Hall, 1997. p. 382-426.

HU, S.J.; PARK, G.B.; JOO, S.T. Biological activities of conjugated linoleic acid (CLA) and effects of CLA on animal products. Livest. Sci., v.110, p.221-229, 2007.

JENKINS, T.C.; WALLACE, R J.; MOATE, P.J.; MOSLEY, E.E. Board-invited review: Recent advances in biohydrogenation of unsaturated fatty acids within the rumen microbial ecosystem. J. Anim. Sci., v.86, p.397412, 2008.

JIANG, Z.Y.; ZHONG, W.J.; ZHENG, C.T. Conjugated linoleic acid differentially regulates fat deposition in backfat and longissimus muscle of finishing pigs. J. Anim. Sci., v.88, p.16941705, 2010.

KRAMER, J.; FELLNER, V.; DUGAN, M.E. et al. Evaluating acid and base catalysts in the methylation of milk from rumen fatty acids with special emphasis on conjugated dienes and total trans fatty acids. Lipids, v.32, p.1219-1228, 1997. 
LI, X.Z.; YANA, C.G.; LEEB, H.G. et al. Influence of dietary plant oils on mammary lipogenic enzymes and the conjugated linoleic acid content of plasma and milk fat of lactating goats. Anim. Feed Sci. Technol., v.174, p.26-35, 2012.

LOCK, A.L.; TELES, B.M.; PERFIELD, J.W. et al. A conjugated linoleic acid supplement containing trans-10, cis-12 reduces milk fat synthesis in lactating sheep. J. Dairy Sci., v.89, p.1525-1532, 2006.

LOOR, J.J.; FERLAY, A.; OTTIER, A. et al. Relationship among trans and conjugated fatty acids and bovine milk fat yield due to dietary concentrate and linseed oil. J. Dairy Sci., v.88, p.726-740, 2005.

LUCAS, A.; ROCK, E.; AGABRIEL, C. et al. Relationships between animal species (cow versus goat) and some nutritional. Small Ruminant Res., v.74, p.243-248, 2008.

MAIA, F.J.; BRANCO, A.F.; MOURO, G.F et al. Feeding vegetable oil to lactating goats: nutrient digestibility and ruminal and blood metabolism. Rev. Bras. Zootec., v.35, p.14961503, 2006

MATSUSHITA, M.; TAZINAFO, N.M.; PADRE, R.G. et al. Fatty acid profile of milk from Saanen goats fed a diet enriched with three vegetable oils. Small Ruminant. Res., v.72, p.127-132, 2007.

MOSLEY, E.E.; SHAFFI, B.; MOATE, P. J. et al. cis-9, trans-11 conjugated linoleic acid is synthesized directly from vaccenic acid in lactating dairy cattle. J. Nutr., v.136, p.570-575, 2006.

NUTRIENT requirements of small ruminants: sheep, goats, cervids, and new world camelids. Washington, DC: National Research Council, 2007. 362p.

OFFICIAL methods of analysis. 15.ed. Washington D.C: AOAC, 1990. 1094p.

PARK, Y.; ALBRIGHT, K; LIU, W. et al. Effect of conjugated linoleic acid on body composition in mice. Lipids, v.32, p.853-858. 1997.

PFEUFFER, M.; SCHREZENMEIR, J. Bioactive substances in milk with properties decreasng risk of cardiovascular diseases. Br. J. Nutr., v.84, p.155-159. 2000.
PETERSON, D.G.; MATITASHVILI, E.A.; BAUMAN, D.E. Diet-induced milk fat depression in dairy cows results in increased trans-10, cis-12 CLA in milk fat and coordinate suppression of mRNA abundance for mammary enzymes involved in milk fat synthesis. J. Nutr., v.133, p.3098-3102, 2003.

REYNOLDS, C.K.; CANNON, V.L.; LOERCH, S.C. Effects of forage source and supplementation with soybean and marine algal oil on milk fatty acid composition of ewes. Anim. Feed Sci. Techn. v.131, p.333-357, 2006.

SCHMIDELY, P.; MORAND-FEHR, P. Effects of intravenous infusion of trans-10, cis 12 or cis9, trans-11 conjugated linoleic acid (CLA) on mil fat synthesis and composition in dairy goats during mid-lactation. S. Afri. J. Anim. Sci., v.34, p. 195-197, 2004.

SINCLAIR, L.A.; LOCK, A.L.; EARLY, R.; BAUMAN, D.E. Effects of trans-10, cis-12 conjugated linoleic acid on ovine milk fat synthesis and cheese properties. J. Dairy Sci., v.90, p.3326-3335, 2007.

SKLAN, D.; ASHKENNAZI, R.; BRAUN, A. et al. Fatty acids, calcium soaps of fatty acids, and cottonseeds fed to high yielding cows. J. Dairy Sci., v.75, p.2463-2472, 1992.

TEDESCHI, L.O.; CANNAS, A.; FOX, D.G. A nutrition mathematical model to account for dietary supply and requirements of energy and nutrients for domesticated small ruminants: the development and evaluation of the small ruminant nutrition System. Rev. Bras. Zootec., v.37, supl. esp., p.178-190, 2008.

USER'S guide: statistics. Versiom. 9.1.1. Cary: SAS, Institute, 2004.

VAN SOEST, P.K.; ROBERTSON, J.B.; LEWIS, B.A. Methods for dietary fiber: neutral detergent fiber and nonstarch polysaccharides in relation animal nutrition. J. Dairy Sci., v.74, p.3583-3597, 1991.

WASOWSKA, I.; MAIA, M.R.G.; NIEDZWIEDZKA, K.M. et al. Influence of fish oil on ruminal biohydrogenation of $\mathrm{C} 18$ unsaturated fatty acids. Br. J. Nutr., v.95, p.1199-1211. 2006. 